\title{
Cell Loss from the Nucleus Basalis of Meynert in Alzheimer's Disease
}

\author{
R. Doucette, M. Fisman, V.C. Hachinski and H. Mersky
}

\begin{abstract}
We examined the degree of neuronal loss from the nucleus basalis of Meynert (nbM) in two groups of Alzheimer patients differing in the degree of intellectual impairment. Significant cell loss from the nbM was found only in the more severely demented group of patients. Mean cell counts (per $10 \mu$ paraffin section) were compiled separately for the anterior, intermediate and posterior subdivisions of the human nbM in three groups of subjects: Group $1(\mathrm{~N}=4)$ was severely demented and was untestable on the Extended Scale for Dementia (ESD) for at least the last two years of life; Group $2(\mathrm{~N}=4)$ was less demented and had completed at least one ESD test within 12 months of death; Group 3 (five controls) had died of non-neurological causes. In Group 2 there was a small (but insignificant) trend toward cell loss in the anterior subdivision, and a normal complement of neurons in both the intermediate and posterior subdivisions. There was, however, significant cell loss from all subdivisions of Group 1 . How these cell counts may relate to the severity of the dementia is discussed.
\end{abstract}

RÉSUMÉ: Perte cellulaire au niveau du nucleus basalis de Meynert dans la maladie d'Alzheimer. Nous avons examiné l'étendue de la perte de neurones au niveau du nucleus basalis de Meynert (nbM) chez deux groupes de patients atteints de la maladie d'Alzheimer et manifestant un degré différent d'atteinte intellectuelle. Nous avons retrouvé une perte cellulaire significative au niveau du nbM seulement dans le groupe de patients dont la démence était plus sévère. Nous avons compilé un décompte cellulaire moyen (par $10 \mu$, de section traitée à la paraffine) pour la partie antérieure, intermédiaire et postérieure du nbM humain chez trois groupes de sujets: le groupe $1(\mathrm{~N}=4)$ souffrait de démence sévère et ces patients n'étaient pas évaluables au moyen de l'échelle élargie pour la démence (EED) pendant une période d'au moins deux ans précédant leur décès; le groupe $2(\mathrm{~N}=4)$ souffrait de démence moins sévère et ces patients avaient pu compléter au moins une épreuve EED pendant les 12 moins précédant leur décès; le groupe 3 (5 témoins) était décédé d'une cause autre (non neurologique). Dans le groupe 2, il y avait une légère tendance (non significative) vers une perte cellulaire au niveau de la région antérieure et un décompte normal des neurones dans les régions intermédiaire et postérieure. Cependant, dans le groupe 1, il y avait une perte cellulaire significative au niveau de toutes les régions du nbM. Nous discutons de la façon dont ces décomptes cellulaires peuvent être reliés à la sévérité de la démence.

Can. J. Neurol. Sci. 1986: 13:435-440

Our interest in the nucleus basalis of Meynert (nbM) in Alzheimer's disease arose as part of an interdisciplinary study that is comparing the severity of pathological changes in several brain regions with the severity of the dementia. In the neocortex of Alzheimer patients the density of neuritic plaques ${ }^{1}$ and neurofibrillary tangle-bearing neurons ${ }^{2}$ increases in proportion to the severity of dementia. Cortical plaque and tangle counts $^{3,4}$ also show a proportional relationship to the degree of neuronal loss from the nbM suggesting that the extent of this cell loss should also vary in accordance to the severity of the cognitive decline. The purpose of this preliminary study was to compare the severity of cell loss from the nbM in two groups of Alzheimer patients who differed in the degree of intellectual impairment.

\section{MEthods aNd MATERials}

More than 200 patients with Alzheimer-type dementia have been enrolled in a study at the University of Western Ontario (U.W.O.) in London, Ontario. All patients undergo neurological and psychiatric assessments, supplemented by periodic psychometric tests (see below) used to quantify the level of mental impairment. We studied the nbM in eight patients in whom dementia had been evident during life and who had neuropathological confirmation of Alzheimer's Disease after death.

\section{Clinical History}

Degree of Cognitive Impairment The degree of cognitive impairment was determined using the Extended Scale for Dementia 
(ESD). The ESD, which measures language disturbances, memory loss and general cognitive dysfunction, ${ }^{5}$ reliably indicates the level of mental impairment. Out of a maximal score of 250 , presumptive Alzheimer patients score progressively lower on the ESD over time, eventually being unable to complete the test. Four brains from patients who were untestable on the ESD during the last two years of life comprised Group 1 (very severe dementia). A further four brains, comprising Group 2, were obtained from less demented patients who had successfully completed at least 1 ESD test within 12 months of death. A control group (Group 3) was formed from the brains of five individuals with no history of neurological or psychiatric illness; these latter individuals were not part of the U.W.O. dementia study and thus had not been administered the ESD.

Neurological Summary The presenting clinical symptoms in all of the Alzheimer patients were memory loss (reported as forgetfulness) and associated confusion. From these initial symptoms all patients then experienced a generalized, progressive deterioration of their cognitive function. At the time of death all patients of Group 1 (see Table 1) were unable to perform even simple tasks of daily living, including getting dressed and maintaining personal hygiene. In general, the patients of Group 2 remained somewhat oriented to place and/or person up until at least a year before death, and although they had poor judgment and insight into their condition and required nursing care, they could feed and clothe themselves, and could respond to simple commands. The patients in Group 3 had died of non-neurological causes and their clinical history showed no evidence of a dementing (or of any other) neurological illness.

\section{Neuropathology}

Harvesting of brain tissue The brains were removed during autopsies performed at University Hospital or one of the affiliated teaching hospitals of U.W.O. (Victoria Hospital and St. Joseph's Hospital). In most cases the cerebral hemispheres and brainstem were bisected in the fresh state in the midsaggittal plane and the left half was fixed in $20 \%$ formalin in phosphate buffer; the right half of each brain was then frozen at $-80^{\circ} \mathrm{C}$ for subsequent use by other investigators. Although one of the control brains was fixed whole in $20 \%$ formalin only the left nbM was studied.

After 7 to $\mathbf{1 0}$ days of formalin fixation, tissue samples were obtained from corresponding regions of the frontal, temporal, parietal and occipital lobes of each brain. The entire anteroposterior extent of the left hippocampal formation was also sampled after it had been removed en bloc from the temporal lobe. The left cerebrum was then sliced serially in the coronal plane, each slice being 3 to $4 \mathrm{~mm}$ thick. The entire left basal forebrain was sampled starting anteriorly at the coronal level of the septum, and continuing to just behind the mammillary body. In addition the posterior thalamus, anterior corpus striatum, hypothalamus, amygdala, midbrain, pons, medulla, cerebellum and (when available) spinal cord were also sampled for neuropathological examination.

Neuropathology summary Routine neuropathological support for the clinical diagnosis of Alzheimer's Disease was obtained from Dr. M.J. Ball (Department of Pathology, U.W.O.). In Groups 1 and 2 (see Table 1) only the left half of the brain was available for neuropathological examination. Macroscopically, these brains showed a mild to moderate degree of generalized cortical atrophy, and patchy atherosclerosis, which was mild to moderate in severity with no significant stenoses (except Case \#4), in the vessels of the circle of Willis. Other than a fairly recent hemorrhagic infarct $(2 \times 3 \times 4 \mathrm{~cm})$ in the left middle and inferior frontal gyri of one brain (Case \#8), there were no other significant macroscopic pathological changes in any of these brains. Microscopically, the hippocampal formation in each brain of Group 1 was severely afflicted with neuritic plaques, neurofibrillary tangles, granulovacuolar degeneration, rod-like bodies of Hirano and nerve cell loss (from the pyramidal layer). Tangles, plaques and cell loss were also prominent in the amygdala, and in the second frontal, inferior temporal and calcarine areas of neocortex. Plaques and/or tangles were also common in the hypothalamus and thalamus. The most common lesions in Group 2 brains were neurofibrillary tangles, neuritic plaques and neuron loss, these being found in the hippocampal formation and amygdala, the calcarine area, and in the inferior temporal and second frontal gyri. Granulovacuolar degeneration and Hirano bodies were also common in the hippocampal formation of all but one of these patients (Case \#5); the hypothalamus and thalamus showed only an occasional neuritic plaque and neurofibrillary tangle. There were no Pick inclusion bodies in either Group 1 or 2; however, a few Lewy inclusion bodies were found in the neurons of the substantia nigra of one brain (Case \#3).

In Group 3 the neuropathological investigation was confined to the left hemisphere for four of the five control brains. In the gross state, there was very mild generalized cortical atrophy only in one brain (Case \#9). Atherosclerotic changes were mild to moderate in the vessels of the circle of Willis, with significant stenoses only in Case \#12. At the microscopic level neuritic plaques, neurofibrillary tangles, granulovacuolar degeneration and Hirano bodies were rare in all brains. In the left occipital lobe of Case \#12 a cystic old infarct $(3.5 \times 3 \times 2 \mathrm{~cm})$ had destroyed much of the cortex, as well as some of the subjacent white matter. In the same brain there were a few small foci of acute ischemic cell loss, mainly within Rose's $\mathrm{Hl}$ field of the hippocampus.

\section{Quantitation of Cell Loss in the Nucleus Basalis of Meynert}

All basal forebrain blocks were embedded in paraffin, serially sectioned at a thickness of $10 \mu$, and every 10 th section mounted onto glass slides. These sections, which were stained with cresyl violet acetate and chromoxane cyanine $\mathrm{R}$ (a myelin stain $)^{6}$, were scanned to identify the anterior, intermediate and posterior subdivisions of the nbM. ${ }^{7}$ The anterior subdivision (Figure 1A) extends from the level of the diagonal band nuclei to the caudal aspect of the crossing of the anterior commissure. The anterior hypothalamus forms the medial border of the intermediate subdivision (Figure 1B), which is bounded dorsally by the globus pallidus, ventrally by the rostral amygdala, and laterally by the posterior limb of the anterior commissure. The posterior subdivision (Figure 1C) lies caudal to the posterior limb of the anterior commissure, dorsolateral to the optic tract, and ventral to the globus pallidus. For cell counts four to eight sections (spaced $100 \mu$ apart) were chosen from the main body of each subdivision; the average number of nucleolated nbM neurons (regardless of size or staining property) per histological section was quantified at $250 \mathrm{X}$ magnification on a Wild M501 sampling stage microscope using a square ocular graticule. These raw cell counts were corrected using Abercrombie's formula. ${ }^{8}$ To compute Abercrombie's correction fac- 


\begin{tabular}{|c|c|c|c|c|c|c|}
\hline \multirow{4}{*}{ I } & \multirow{4}{*}{ Severe } & 1. & 74 & 13 & $\mathbf{M}$ & 1150 \\
\hline & & 2. & 80 & 12 & $\mathbf{M}$ & 1205 \\
\hline & & 3. & 83 & 5 & $\mathrm{~F}$ & 1205 \\
\hline & & 4. & 85 & 14 & $\mathrm{~F}$ & 875 \\
\hline \multirow{5}{*}{ II } & \multirow{5}{*}{ Less severe } & 5. & 63 & 6 & M & 1040 \\
\hline & & 6. & 78 & 8 & $\mathrm{~F}$ & 1020 \\
\hline & & 7. & 79 & 11 & $\mathrm{~F}$ & 1310 \\
\hline & & 8. & 82 & 11 & $\mathrm{~F}$ & 1180 \\
\hline & & $\begin{array}{l}\text { Mean } \\
\pm \text { SEM }\end{array}$ & $\begin{array}{r}75.5 \\
\pm 4.9\end{array}$ & $\begin{array}{r}9.0 \\
\pm 1.4\end{array}$ & & $\begin{array}{r}1137.5 \\
\pm 78.1\end{array}$ \\
\hline \multirow{2}{*}{ III } & \multirow{2}{*}{ Absent } & 13. & 95 & - & $\mathbf{M}$ & 1254 \\
\hline & & $\begin{array}{c}\text { Mean } \\
\pm \text { SEM }\end{array}$ & $\begin{array}{r}76.0 \\
\pm 6.0\end{array}$ & & & $\begin{array}{r}1322.8 \\
\pm 144.0\end{array}$ \\
\hline
\end{tabular}

tor the mean maximum nucleolar diameter of at least 100 neurons in each subdivision of the nbM was measured on a HIPAD digitizer that was connected to an Apple IIc minicomputer.

In monkeys ${ }^{7}$ and humans ${ }^{9}$ the majority of $n b M$ neurons are cholinergic, suggesting that the use of immunohistochemical techniques to count cholinergic neurons ${ }^{10,11}$ might have been more appropriate. However, while an immunohistochemical stain for ChAT would permit identification of these cholinergic neurons in the brain of a non-demented person, decreased levels of this enzyme in Alzheimer's Disease ${ }^{12,13}$ make it less reliable as a marker in the nbM of Alzheimer patients. We therefore felt that immunohistochemical and/or biochemical studies on ChAT had to wait until more was known about the factors determining the extent of involvement of the nbM, which is comprised also of non-cholinergic neurons, in the pathogenesis of Alzheimer's Disease.

The cell counts in Groups 1 (severely demented), 2 (less demented) and 3 (control) were analyzed using a two-way analysis of variance. The two independent variables were: 1) severity of dementia, and 2) subdivision of nbM.

\section{RESUlTS}

Serial sections through the basal forebrain blocks were scanned to identify the anterior, intermediate and posterior subdivisions of the $\mathrm{nbM}$ in each brain. Then four to eight sections (spaced $100 \mu$ apart) were chosen from the main body of each subdivision, the number of nucleolated neurons were counted, and the average number of cells per $10 \mu$ histological section quantified. Group means ( \pm S.E.M.) were calculated using these average cell counts. Neurons in each of the three subdivisions were counted in both Groups 1 and 2 (except Case \#7), but in Group 3 (control) the sections did not include the anterior subdivision in one brain (Case \#12) and the posterior subdivision of a second brain (Case \#13).

The results are shown in Figure 2. An analysis of variance revealed a significant group effect $(p<0.001)$ as well as a significant subdivision effect $(\mathrm{p}<0.001)$. The latter result was due to the fact that even in control subjects the mean cell counts per histological section got progressively lower from the anterior $(266.3 \pm 44.7)$ through the intermediate $(132.7 \pm 7.8)$ to the posterior $(90.6 \pm 16.2)$ subdivision. Our primary interest was a comparison between groups, so we did a posthoc analysis on the cell counts of each group at each subdivision. This posthoc analysis revealed that none of the cell counts for Group 2 (i.e. less demented patients) were significantly less than those of Group 3 (Dunn test, $p>0.05$ ), whereas all the counts for Group 1 were indeed significantly smaller (Dunn test, $p<0.006$ ). The cell counts for Groups 1 and 2 were significantly different only at the intermediate and posterior subdivisions of the nbM (Dunn test, $\mathrm{p}<0.006$ ).

\section{Discussion}

In the intermediate and posterior subdivisions, but not in the anterior portion of the $\mathrm{nbM}$, the degree of neuronal loss increases in accordance with the severity of the dementia. Thus, the Group 2 Alzheimer patients (although demented) contained a normal complement of neurons in the intermediate and posterior subdivisions, whereas the more severely demented patients of Group 1 had significantly fewer neurons in these two locations. In contrast, the mean cell counts for the anterior subdivision of Groups 1 and 2 were not statistically different, nor was the mean cell count for the anterior subdivision of Group 2 significantly different from that of the control group, even though a visual inspection of Figure 2 is suggestive of cell loss. However, the fact that the latter difference did not reach statistical significance may be due to the small number of brains examined. Thus, we must allow for the possibility that neuronal loss occurs earlier in the anterior portion of the nbM than it does in either the intermediate or posterior subdivisions.

\section{A Comparison With Previous Studies}

The nbM is undoubtedly involved in the pathogenesis of Alzheimer's Disease, ${ }^{14.15}$ but the true extent of this involvement has yet to be rigorously determined; the reports have 


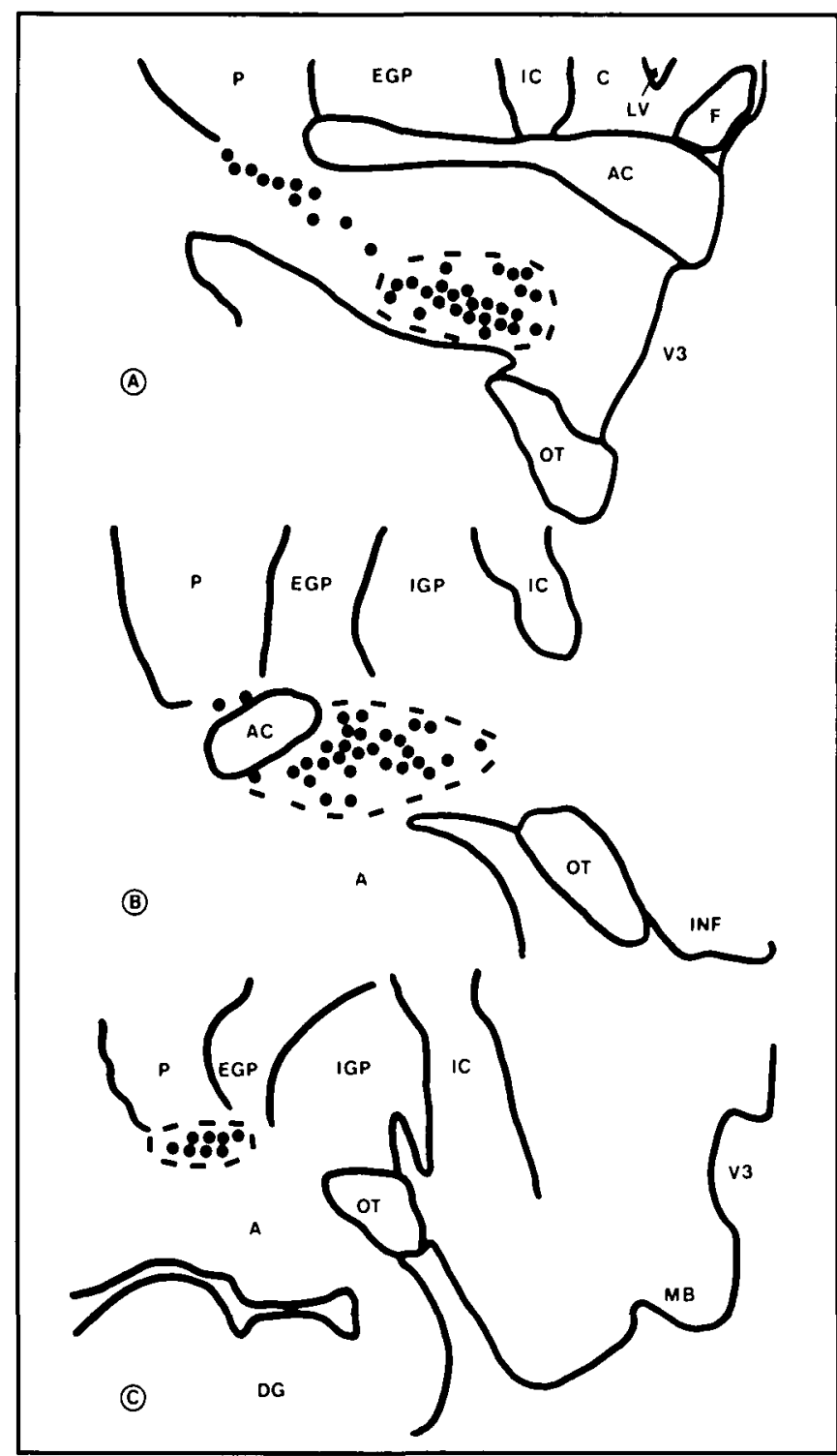

Figure I - Diagram showing the distribution of neurons in three representative coronal sections through the anterior $(A)$, intermediate $(B)$ and posterior $(C)$ subdivisions of the nbM for case \#9 (see Table I). In each figure the dashed lines indicate the borders of each respective subdivision. The positions of interstitial neurons (e.g. in the medullary laminae) are not indicated. The location of clusters of magnocellular neurons (i.e. $>30 \mu$ long) was used to indicate the position and extent of the $n b M$ in each histological section. All neurons, regardless of size or staining properties, that fell within $200 \mu$ of these cell clusters were considered part of the nbM. In A the neurons lateral to the enclosed area appear to be a rostral extension of the intermediate group, but were not included in the morphometric analysis of either cell group. The sections were traced using an $X-Y$ recorder that was connected to the sampling stage of a Wild-Leitz M50I semi-automated microscope by means of two linear potentiometers. Each ink dot denotes the position of about 10 nucleolated nbM neurons.

Abbreviations:
A - amygdala
$A C$ - anterior commissure
C - caudate
$F \quad$ - fornix
$E G P$ - external globus pallidus
IGP - internal globus pallidus
V3 - third ventricle

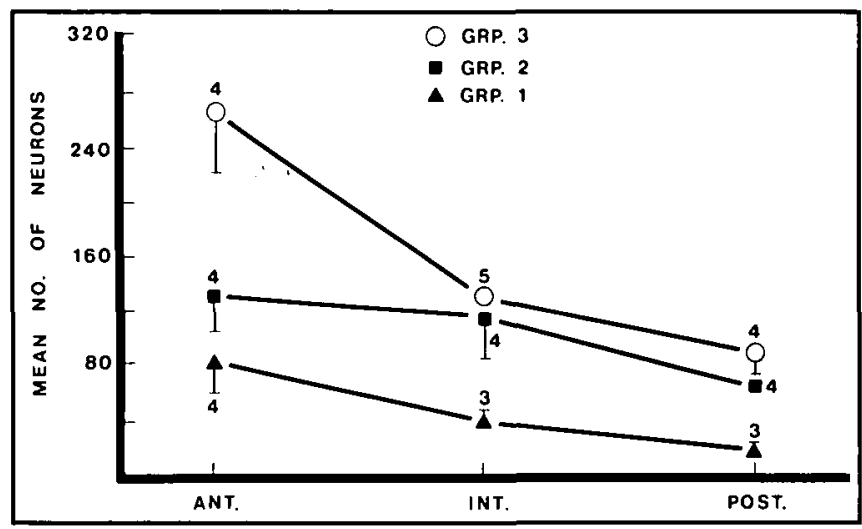

Figure $2-$ The mean number ( \pm SEM) of nucleolated neurons per $10 \mu$ histological section at each subdivision of the left $n b M$ for each of groups 1,2 and 3 (see Table 1). These mean cell coums were derived as follows. For each brain, the relevant neurons were counted in four to eight histological sections, these counts were corrected using Abercrombie' $s^{8}$ formula, and the average number of cells per $10 \mu$ paraffin section was calculated. Each symbol thus represents the mean of three to five average corrected cell counts; the number by each symbol indicates the number of brains that were examined. See the text for a description of the statistical analysis.

varied from an insignificant $18 \%$ decrease ${ }^{10}$ to an extensive $90 \%$ depletion. ${ }^{16}$ At least two factors probably contribute to this variability. First, our data suggest that variable degrees of cell loss would be the expected result if the patient population were heterogeneous in terms of the severity of dementia. Using a retrospective analysis of the clinical records previous studies could only determine the general mental ability of each patient and thus could not categorize the brains in terms of the severity of the cognitive decline. Thus, the variability may be due, at least partially, to the sampling of patients with different levels of intellectual impairment; i.e., at different stages in the disease process.

Second, it is probable that variations in methodological design also contributed to the variability in degree of cell loss. For example, only Tagliavini and Pilleri ${ }^{17}$ and Arendt $e t a l^{18}$ used Abercrombie's ${ }^{8}$ correction factor to control for differences in nucleolar size. Those studies not correcting for split nucleoli probably exaggerated the extent of cell loss because the nucleolar volume in nbM neurons is generally reduced by $30-35 \%$ in the brains of Alzheimer patients. ${ }^{17.19}$ Furthermore, the various studies did not examine comparable parts of the nbM. Each study usually examined only a few histological sections per brain and extrapolated to the whole nbM..$^{10.16 .17 .20-25}$ In the absence of a more extensive evaluation of the $\mathrm{nbM}$, which extends for about $15 \mathrm{~mm}$ in the rostrocaudal direction, it is impossible to estimate the extent to which the whole nuclear group may be involved in Alzheimer's Disease. For this reason we chose to look at three different subdivisions of the nbM in each brain. A third criticism is that several of the studies ${ }^{20.22-25}$ counted only the magnocellular neurons (i.e. $>30 \mu$ long), which on average account for only $60 \%$ of the total number per histological section in each of the three subdivisions (R. Doucette, unpublished data). A few additional reports counted all "large" nucleolated nbM neurons, but failed to state their size criteria. ${ }^{\mid 6-18}$ The cell atrophy that is reported to occur in the nbM in Alzheimer's Disease ${ }^{17.19}$ makes this size factor an invalid criterion for exclusion from the sample. Although the magnocellular neurons may ultimately prove to play a more important role in the disease 
process, it is methodologically unsound to randomly exclude neurons from the study simply on the basis of cell size. In fact, according to Mesulam et $a l^{7}$ both large and small nbM neurons (in the monkey brain) stain immunohistochemically for ChAT and members of both cell populations have direct projections to the neocortex. It was for these reasons that we chose to count all nucleolated nbM neurons. Finally, the controls of Tagliavini and Pilleri ${ }^{17}$ and of Nagai et al ${ }^{11}$ were thirteen years younger than their group of Alzheimer patients. Cell numbers in the nbM normally decrease with age ${ }^{9}$ (however, see Chui et $a^{26}$ ), so these age differences could have exaggerated any observed neuronal "fall-out", which the authors attributed to Alzheimer's Disease.

\section{Concluding Statement}

If pathological changes in the nbM in Alzheimer's Disease contribute to the dementia from disease onset until death, then the mechanism by which this occurs may differ for the early and the later stages of the disease. For example, insofar as cell loss may relate to intellectual impairment, it is unlikely that a loss of neurons from the intermediate and posterior subdivisions contributes to the initial cognitive decline that occurs in Alzheimer's Disease. Thus, during the initial stages it may be abnormally functioning nbM neurons that contribute to the cognitive decline, while in later stages the most significant pathological change in the intermediate and posterior subdivisions would be an actual loss of neurons. Our data leave open the question of whether cell loss from the anterior subdivision may contribute to the mental impairment during early stages of the disease. In addition, our findings have important implications in regard to the results of previous neurochemical studies. Cortical ChAT loss can occur very early in the clinical presentation of Alzheimer's Disease $^{27}$ and may in fact occur with little or no enzyme loss in the nbM itself. ${ }^{21}$ Perhaps nbM neurons, at least during the initial stages of the disease, continue to synthesize normal quantities of ChAT but simply fail to transport it to their terminals. Although we only examined the left nbM, the study of Arendt $e t$ $a l,{ }^{28}$ in which the same three subdivisions of both the right and left nbM were examined, suggests that any cell loss is probably bilaterally symmetrical. Nevertheless, any attempt to study these clinical and neurochemical implications should take special care to include an examination of both the right and left nbM in each brain.

\section{ACKNOWLEDGEMENTS}

This work was supported by grants from the Ontario Mental Health Foundation (to R.D.), the Bickel Foundation (to Dr. M.J. Ball), the Medical Research Council of Canada (PG-21, to Dr. M.J. Ball) and the National Institutes of Health (AGNS 03047, to Dr. M.J. Ball). We thank Drs. A.C. Wallace, J. Frei, D. Turnbull, C. Anderson, M. Silver, D. Banerjee, R. Armstrong, V. Walley, and D.T. Shum for their provision of some of the necropsy tissues; and Drs. N. Jaatoul, R. Cape, A. Hahn, V.A. Kral, R.B. Palmer, J. Sales, G. Perkin, C.R. Green, A. Kirshen, D.J. Harris, A. Hunter and J. Brown for referring patients to the Study. Thanks are also due to Dr. M.J. Ball for providing the neuropathology diagnoses, to Mr. B. Nagy, Mrs. J. MacGregor, Mrs. M. Murphy and Ms. P. Tozer for their technical assistance, to Mrs. Claudette Stroeder and Mrs. Irene Partridge for the typing of the manuscript, and to Drs. M.J. Ball and I. Munkacsi for reading a draft of the manuscript.

\section{REFERENCES}

1. Blessed G, Tomlinson BE and Roth $M$. The association between quantitative measures of dementia and of senile change in the cerebral grey matter of elderly subjects. Brit J Psych 1986; 114: 797-811.

2. Wilcock GK and Esiri MM. Plaques, tangles and dementia: $A$ quantitative study. J Neurol Sci 1982; 56: 343-356.

3. Arendt T, Bigl V, Tennstedt A and Arendt A. Correlation between cortical plaque count and neuronal loss in the nucleus basalis in Alzheimer's disease. Neurosci Lett 1984; 48(1): 81-86.

4. Mann DM, Yates PO and Marcyniuk B. Correlation between senile plaque and neurofibrillary tangle counts in cerebral cortex and neuronal counts in cortex and subcortical structures in Alzheimer's Disease. Neurosci Lett 1985; 56: 51-55.

5. Hersch EL. Development and application of the extended scale for dementia. J Amer Ger Soc 1979; 28: 348-354.

6. Kiernan JA. "Histological and Histochemical Methods", Oxford: Pergamon Press.

7. Mesulam M-M, Mufson EJ, Levey AI and Wainer BH. Cholinergic innervation of cortex by the basal forebrain: Cytochemistry and cortical connections of the septal area, diagonal band nuclei, nucleus basalis (substantia innominata) and hypothalamus in the rhesus monkey. J Comp Neurol 1983; 214: 170-197.

8. Abercrombie M. Estimation of nuclear population from microtome sections. Anat Rec 1946; 94: 239-247.

9. McGeer PL, McGeer EG, Suzuki J, Dolman CE and Higai T. Aging, Alzheimer's disease, and the cholinergic system of the basal forebrain. Neurol 1984; 34(6): 741-745.

10. Pearson RC, Sofroniew MV, Cuello AC, Powell TP, Eckenstein F, Esiri MM and Wilcock G. Persistence of cholinergic neurons in the basal nucleus in a brain with senile dementia of the Alzheimer's type demonstrated by immunohistochemical staining for choline acetyl-transferase. Brain Res 1983; 289: 375-379.

11. Nagai I, McGeer PL, Peng JH, McGeer EG and Dolman CE. Choline acetyltransferase immunohistochemistry in brains of Alzheimer's disease patients and controls. Neurosci Lett 1983; 36: 195-199.

12. Wilcock GK, Esiri MM, Bowen DM and Smith CC. Alzheimer's disease: Correlation of cortical choline acetyltransferase activity with the severity of dementia and histological abnormalities. J Neurol Sci 1982; 57: 407-417.

13. Candy JM, Perry RH, Perry EK, Irving D, Blessed G, Fairbairn $\mathrm{AF}$ and Tomlinson BE. Pathological changes in the nucleus of Meynert in Alzheimer's and Parkinsons's diseases. J Neurol Sci $1983 ; 277-289$.

14. Ezrin-Waters $C$ and Resch $L$. The nucleus basalis of Meynert. Can J Neurol Sci 1986; 13: 8-14.

15. Perry EK. The cholinergic hypothesis: Ten years on. Brit Med Bull 1986, 42: 63-69.

16. Whitehouse PJ, Price DL, Clark AW, Coyle JT and DeLong MR. Alzheimer's disease: Evidence for selective loss of cholinergic neurons in the nucleus basalis. Ann Neurol 1981; 10: 122-126.

17. Tagliavini F and Pilleri G. Basal nucleus of Meynert: A neuropathological study in Alzheimer's disease, simple senile dementia, Pick's disease and Huntington's chorea. J Neurol Sci 1983; 62(1-3): 243-260.

18. Arendt T, Bigl V, Arendt A and Tennstedt A. Loss of neurons in the nucleus basalis of Meynert in Alzheimer's disease, paralysis agitans and Korsakoff's disease. Acta Neuropath 1983;61: 101-108.

19. Mann DM and Yates PO. Is the loss of cerebral cortical CAT activity in Alzheimer's disease due to degeneration of ascending cholinergic nerve cells? J Neurol Neurosurg Psychiat 1982; 45: 936-943.

20. Whitehouse PJ, Price DL, Struble RG, Clark AW, Coyle JT and DeLong MR. Alzheimer's disease and senile dementia: Loss of neurons in the basal forebrain. Science 1982; 215: 1237-1239.

21. Perry RH, Candy JM, Perry EK, Irving D, Blessed G, Fairburn AF and Tomlinson BE. Extensive loss of choline acetyltransferase activity is not reflected by neuronal loss in nucleus of Meynert in Alzheimer's disease. Neurosci Lett 1982; 33: 311-315.

22. Wilcock GK, Esiri MM, Bowen DM and Smith CC. The nucleus basalis in Alzheimer's disease: Cell counts and cortical biochemistry. Neuropath Appl Neurobiol 1983; 9: 175-179. 
23. Mann DM, Yates PO and Marcyniuk B. Changes in nerve cells of the nucleus basalis of Meynert in Alzheimer's Disease and their relationship to aging and to the accumulation of lipofuscin pigment. Mech Ageing Devel 1984a; 25: 189-204.

24. Mann DM, Yates PO and Marcyniuk B. Alzheimer's presenile dementia, senile dementia of Alzheimer type and Down's syndrome in middle age form an age related continuum of pathological changes. Neuropath Appl Neurobiol 1984b; 10(3): 185-208.

25. Mann DM, Yates $P O$ and Marcyniuk B. A comparison of changes in the nucleus basalis and locus coeruleus in Alzheimer's disease. J Neurol Neurosurg Psychiat 1984c; 47(2): 201-203.
26. Chui HC, Bondareff W, Zarow $\mathrm{C}$ and Slager U. Stability of neuronal number in the human nucleus basalis of Meynert with age. Neurobiol of Aging 1984; 5: 83-88.

27. Bowen DM, Allen SJ, Benton JS, et al. Biochemical assessment of serotonergic and cholinergic dysfunction and cerebral atrophy in Alzheimer's Disease. J Neurochem 1983; 41: 261-272.

28. Arendt T, Bigl V, Tennstedt A, et al. Neuronal loss in different parts of the nucleus basalis is related to neuritic plaque formation in cortical target areas in Alzheimer's Disease. Neurosci $1985 ; 14: 1-14$. 